\title{
Structure and Filtration Performances of Improved Cuprammonium Regenerated Cellulose Hollow Fiber (Improved BMM Hollow Fiber) for Virus Removal
}

\author{
Takashi Tsurumi, Tetsuo Sato, Naoki Osawa, \\ Hidetoshi Hitaka, Tomoko Hirasaki, Kazuhito Yamaguchi,* \\ Yoshiaki Hamamoto, ${ }^{* *}$ Sei-ichi Manabe, Takashi Yamashiki, \\ and Naoki YAMAMOTO***
}

\author{
BMM Project, Fibers and Textiles Administration, Asahi Chemical Industry Co., Ltd., \\ The Imperical Tower 18F, 1-1 Uchisaiwaicho 1-chome, Chiyodo-ku, Tokyo 100, Japan \\ *Institute of Laboratory Animals, Yamaguchi University School of Medicine, \\ Ube, Yamaguchi 755, Japan \\ **Department of Virology and Parasitology, Yamaguchi University School of Medicine, \\ Ube, Yamaguchi 755, Japan \\ ***Department of Microbiology, Tokyo Medical and Dental University School of Medicine, \\ 1-5-45 Yushima, Bunkyo-ku, Tokyo 113, Japan
}

(Received May 21, 1990)

\begin{abstract}
To get higher performances of virus removability and permeability of protein than those of the previous cuprammonium regenerated cellulose hollow fiber (referred to as BMM) novel spinning conditions such as minimerized tension loaded on a fiber in addition to high accurate control of temperature and composition were employed (the novel BMM hollow fiber thus obtained is referred to as $\mathrm{i}-\mathrm{BMM}$ ). Comprehensive analysis of the pore structure of $\mathrm{i}-\mathrm{BMM}$ using electron microscope and its filtration characteristics concerning to virus removability and protein permeability indicated that (1) the degree of orientation of the cellulosic substrate and "voids" in i-BMM to the direction of the fiber axis decreased comparied with that of BMM and this led to the disappearance of the breakage of the cellulosic wall between neighbouring voids, (2) the size of the capillary of i-BMM was larger than that of BMM, (3) the virus removability of i-BMM for Japanese encephalitis virus was about $10^{3}$ times BMM when the comparison was made under the same mean pore size. These indicate that the existence probability of "voids" linking side by side and penetrating the membrane from the inner to the outer surface decreased for $\mathrm{i}-\mathrm{BMM}$ and this is the reason $\mathrm{i}-\mathrm{BMM}$ is superior to BMM in virus removal.
\end{abstract}

KEY WORDS Regenerated Cellulose / Hollow Fiber / Electron Micrography / Gold Particle / Virus / Protein /

Because of the complexity of pore structure and difficulty to investigate pore structure, most theoretical approaches or practical interpretations for membrane permselectivity have based their structures on a straightthrough cylindrical pore model. ${ }^{1}$ It is nearly impossible to explain high performance of microporous cuprammonium regenerated cellulose hollow fiber (referred to as BMM in short $)^{2-4}$ in virus removability and protein permeability by this simple model. This indicates sophisticated investigation about pore structure of actual membrane is necessary for better understanding of the high performance of BMM and for improvement to get higher performance.

We investigated the pore structure of BMM using an electron microscope ${ }^{5}$ and the 
mechanism of the capture of particles by this BMM employing the monodisperse gold particles as a model substance of virus. ${ }^{6}$ The results are summerized as follows:

(1) There are two types of pores in BMM. One is "capillaries" with a diameter of several tens $\mathrm{nm}$, scattering everywhere in the membrane and constructing network-like passages and the other is "voids" with the diameter of several hundreds $\mathrm{nm}$ having bulky block-like shape. $^{5}$

(2) "Channels" composed of "voids" continuously linking side by side and penetrating membrane from the inner to the outer surface are formed by elongation of fibers in a direction parallel to the fiber axis during spinning. ${ }^{5}$

(3) The capture mechanism of the particles such as gold particles and viruses by BMM is classified, as plugging in "capillaries" and trapping in "voids". 6

(4) "Channels" composed of "voids" play the role of a pathway for viruses resulting in decrease in the virus removability. ${ }^{5}$

(5) The membrane which has "neuronic capillary-void structure" near the outer surface can be considered ideal for virus removal. This ideal structure may be realized by minimizing elongation of fibes during spinning. ${ }^{5}$

In this paper, we show the effect of minimization of elongation of fibers during spinning on the pore structure of hollow fibers and also verify the superior performances of the fiber thus obtained comparing with BMM and prove the reliability of "neuronic capillaryvoid model" as the ideal membrane structure for virus removal.

\section{EXPERIMENTAL}

\section{Sample Preparation}

(a) BMM and i-BMM. BMM was prepared from cellulose cuprammonium solution through the microphase separation method under strict control of the spinning condition ${ }^{7}$. i-BMM was prepared under spinning conditions carefully designed not to elongate the fiber during spinning along the fiber axis in addition to the same conditions as that applied for BMM. $^{8}$ The inner diameter, membrane thickness and the mean pore size $\left(2 \bar{r}_{\mathrm{f}}\right)$ of $\mathrm{i}-\mathrm{BMM}$ used for this study was $330 \mu \mathrm{m}, 35 \mu \mathrm{m}$, and $40 \mathrm{~nm}$, respectively. Hollow fibers were bundled into S-module and M-module having effective filtration area of $0.6 \mathrm{~cm}^{2}$ and $0.03 \mathrm{~m}^{2}$, respectively.

(b) Monodisperse Gold Particles. The particles with a given size were prepared through the reduction of a gold compound of $\mathrm{HAuCl}_{4}$. Although, the principle of the preparation is given in the literature, ${ }^{9}$ we employed a minor improved method by addition of polyethylene glycol with average molecular weight of 20,000 in order to make stable dispersed solution. The particle size was observed by transmission electron microscope. Some characteristic values of the samples of G20, G30, G50, and G60 were given in the previous paper, ${ }^{6}$ and the numbers attached to symbol $\mathrm{G}$ indicate nominal mean particle size in $\mathrm{nm}$.

(c) Japanese Encephalitis Virus. Japanese encephalitis virus (nominal particle size is $45 \mathrm{~nm}$ in diameter) for vaccination was prepared from Pekin strain and its titer was evaluated by TCID $_{50}$ using BHK-21 cell line. The titer of the original solution was $10^{10.5}$ $\mathrm{TCID}_{50} \mathrm{ml}^{-1}$.

(d) Human Fresh Plasma. Human fresh blood of $400 \mathrm{ml}$ was donated by a volunteer and after centrifugation under $4000 \mathrm{G}$ at $4^{\circ} \mathrm{C}$ for 10 minutes fresh plasma of about $250 \mathrm{ml}$ was obtained.

\section{Measurement}

(a) Pore Characteristics. The mean pore size $2 \bar{r}_{\mathrm{f}}$ was calculated using eq 1 by observed values of the filtration rate of water $J(\mathrm{ml} / \mathrm{min})$, wall thickness $d(\mu \mathrm{m})$, viscosity of water $\eta$ (centipoise), transmembrane pressure $\Delta P$ $(\mathrm{mmHg})$, effective filtration area $A\left(\mathrm{~m}^{2}\right)$ and porosity determined by apparent density of BMM $P_{\mathrm{r} \rho}(-)$, 


$$
2 \overline{r_{\mathrm{f}}}=2.0 \times\left(J \cdot d \cdot \eta / \Delta P \cdot A \cdot P_{\mathrm{r} \rho}\right)^{1 / 2}
$$

\section{(b) Filtration}

i) Filtration of gold particles

The filtrations were carried out through the dead end filtration method using S-modules ${ }^{4}$ under a constant pressure of $100 \mathrm{mmHg}$ at $20^{\circ} \mathrm{C}$. The dependence of the concentration of gold particles in the filtrate on filtration time, volume and the concentration of gold particles in original solution was investigated.

ii) Filtration of plasma

The filtrations were carried out through the dead end filtration method using M-modules ${ }^{3,4}$ under a constant pressure of $150 \mathrm{cmAq}$ at $20^{\circ} \mathrm{C}$. The dependence of the concentration of plasma components in the filtrate on filtration time was investigated.

(c) Electron Microscopy

i) Positive image ${ }^{5}$

i-BMM was immersed in a mixture of methylmethacrylate, buthylmethacrylate and initiator. After polymerization the preparation was sliced into thin sections with thickness of several $\mu \mathrm{m}$ through ultramicrotome ("Ultratome III" manufactured by LKB Co., Ltd., Sweden) using diamond knife ("Diatome"). The sliced sections were three planes of $X Y$, $Y Z$, and $Z X$ profiles (plane axes parallel to the peripheral direction, radial direction, and fiber axis, respectively) shown in Figure 1. The sections were immersed in chloroform to wash the embedded polymer thouroughly and then observed using a scanning electron microscope ("S-570" manufactured by Hitachi Co., Ltd., Japan).

ii) Negative image ${ }^{5}$

The section of $Z X$ profile (i.e., the plane perpendicular to $Y$ axis) of i-BMM was prepared just the same way as above. The sliced section was immersed in cuprammonium solution to solve cellulose but leave the embedded polymeric resin and was observed by a scanning electron microscope ("S-900" manufactured by Hitachi Co., Ltd., Japan).

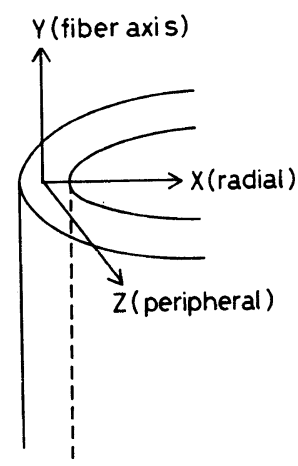

Figure 1. Schematic representation of three axes of $X$, $Y$, and $Z$ in Cartesian coordinate in a hollow fiber: $X$, radial axis; $Y$, fiber axis; $Z$, peripheral axis.

\section{iii) Frozen fractured image 5}

i-BMM was fractured along the direction perpendicular to the fiber axis and parallel to $Z$ axis in liquid nitrogen. The fractured sections (nearly parallel to $Z X$ plane and $X Y$ plane) with Pt coating were observed by a scanning electron microscope (S-570).

iv) Distribution of gold particles in $\mathrm{i}-\mathrm{BMM}$

The frequency distribution of the gold particles present in i-BMM was observed through transmission electron microscopy of the ultrathin cross section of i-BMM after filtration. The section with thickness of 60 to $80 \mathrm{~nm}$ was prepared by an ultramicrotome ("Ultratome III") using a diamond knife ("Diatome").

(d) Distribution of Pore Diameter. The distribution of pore diameter was evaluated from the electron micrograph of the positive image using a graphic data processor ("EO100" manufactured by Eiko Industrial Co., Ltd., Japan).

(e) Size of Gold Particles. The size of gold particles was evaluated by electron microscopy.

(f) Concentration of Gold Particles. The concentration of gold particles was measured using spectrophotometry at $530 \mathrm{~nm}$ of wave length.

(g) Concentration of Proteins. All the plasma before and after filtration were subdivided into suitable sample tubes on ice. The 
concentrations of total protein, albumin, and cholesterol were evaluated with autoanalyzer ("ACA8000" manufactured by Olympus Co., Ltd., Japan). The concentration of IgA. $\mathrm{IgG}, \mathrm{IgM}$, and fibronectin were determined by turbidimetric immunoassay (Boehringer Mannheim Yamanouchi (BMY), Japan). The concentration of antithrombin III was determined by chromogenic synthetic substrate assay. Fibrinogen assay was performed through the thrombin time method using a multifibrin test kit (Behring Behrke, West Germany).

\section{RESULTS AND DISCUSSION}

\section{Analysis of Pore Sturucture}

Figures 2 and 3 show scanning electron micrographs of the frozen fractured sections whose planes are nearly parallel to the $Z X$ plane and $X Y$ plane, respectively. The micrographs marked with (a), (b), and (c) in Figures 2 and 3 correspond to those near the outer, the center and inner surfaces of the membrane, respectively.

In all micrographs in Figure 2, many cellulose particles of round shape with various diameters ranging between $15 \mathrm{~nm}$ and $100 \mathrm{~nm}$ can be seen. In the micrograph (c) in Figure 2 thin cellulose rods having a diameter of $c a$. $10 \mathrm{~nm}$ lying parallel to the peripheral direction can be seen other than cellulose particles of round shape.

In micrographs (a) and (b) in Figure 3, cellulose particles of round shape can be seen. This indicates that the cellulose particles of round shape observed in Figures 2 and 3 have the form of spheres and that $\mathrm{i}-\mathrm{BMM}$ was prepared under the spinning condition so that the fiber was not elongated. In all micrographs in Figure 3 cellulose rods lying parallel to the fiber axis can be seen other than cellulose spheres. In addition to these spheres and rods, large amounts of tiny spots having diameter of ca. $10 \mathrm{~nm}$ can be observed on the cellulose spheres in all micrographs in Figure 3. Judging from their size, these spots are considered to

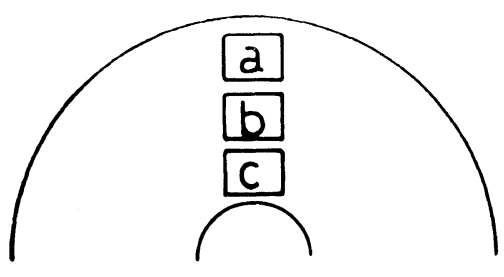

O. S.
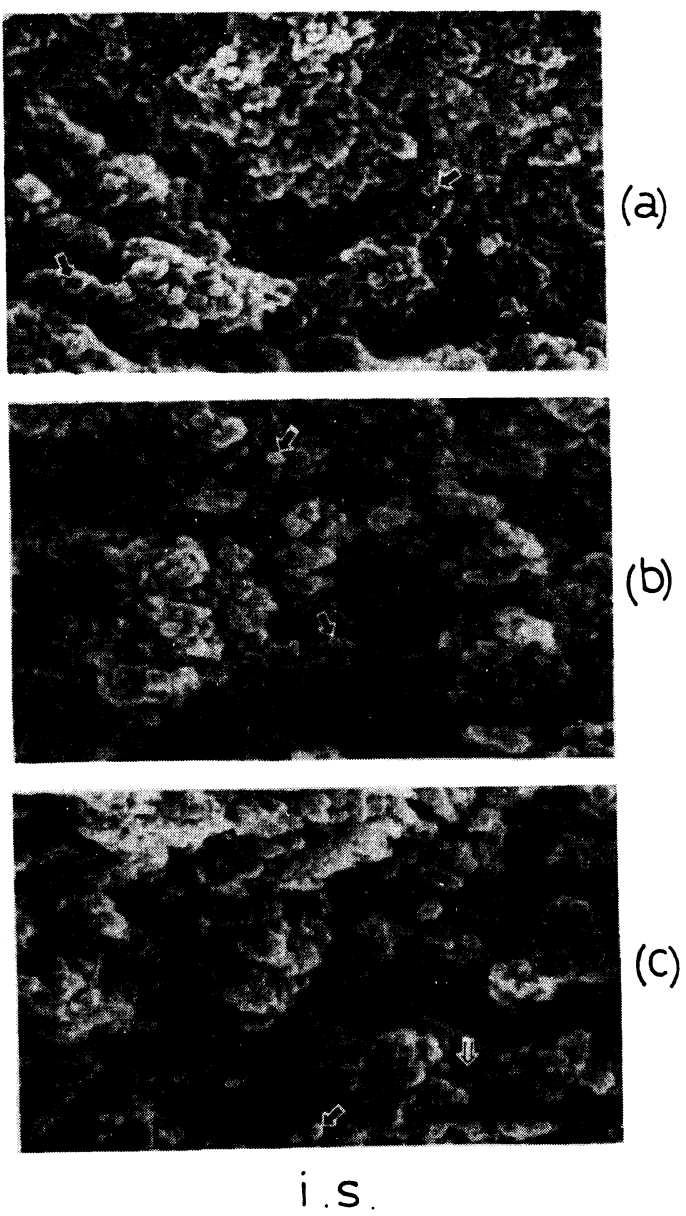

Figure 2. Scanning electron micrographs of frozen fractured sections parallel to $Z X$ plane (perpendicular to fiber axis $Y$ ) obtained by breakage of i-BMM: (a), near the outer surface; (b), near the center of the membrane; (c), near the inner surface. The arrows $\Rightarrow$ and $\Rightarrow$ indicate a cellulose particle of round shape and a thin cellulose rod, respectively. The symbols of o.s. and i.s. stand for outer and inner surfaces, respectively. The scale bar is $500 \mathrm{~nm}$ in length. 


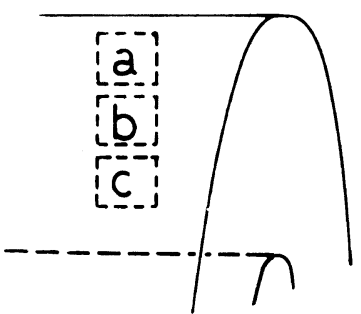

O.S.

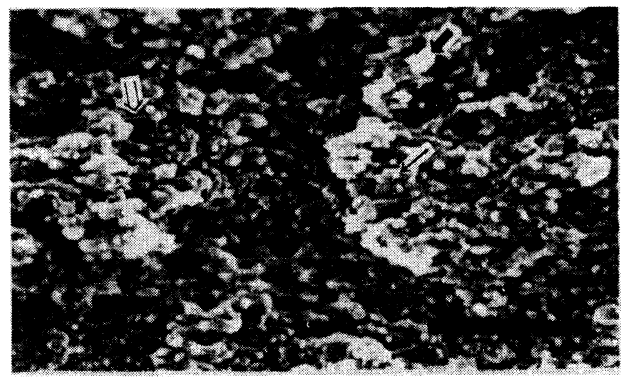

(a)

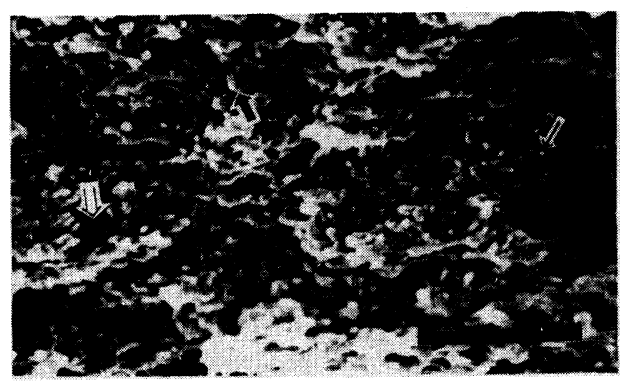

(b)

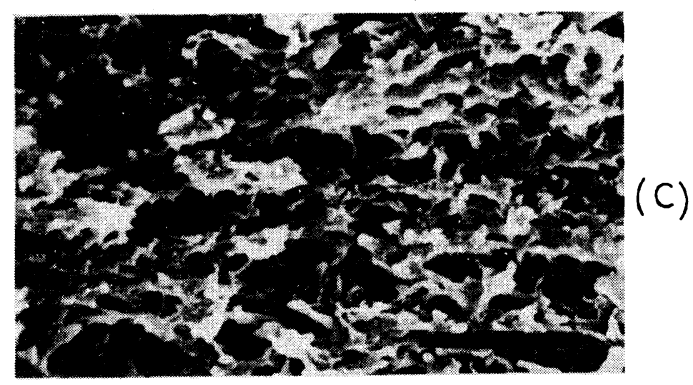

\section{i. 5}

Figure 3. Scanning electron micrographs of frozen fractured section parallel to $X Y$ plane (perpendicular to peripheral axis $Z$ ) obtained by breakage of i-BMM:

(a), near the outer surface; (b), near the center of the membrane; (c), near the inner surface. The arrows $\Rightarrow, \Rightarrow$ and $\rightarrow$ indicate a cellulose particle of round shape, a thin cellulose rod and a tiny spot, respectively. The symbols of o.s. and i.s. stand for outer and inner surfaces, respectively. The scale bar is $500 \mathrm{~nm}$ in length.
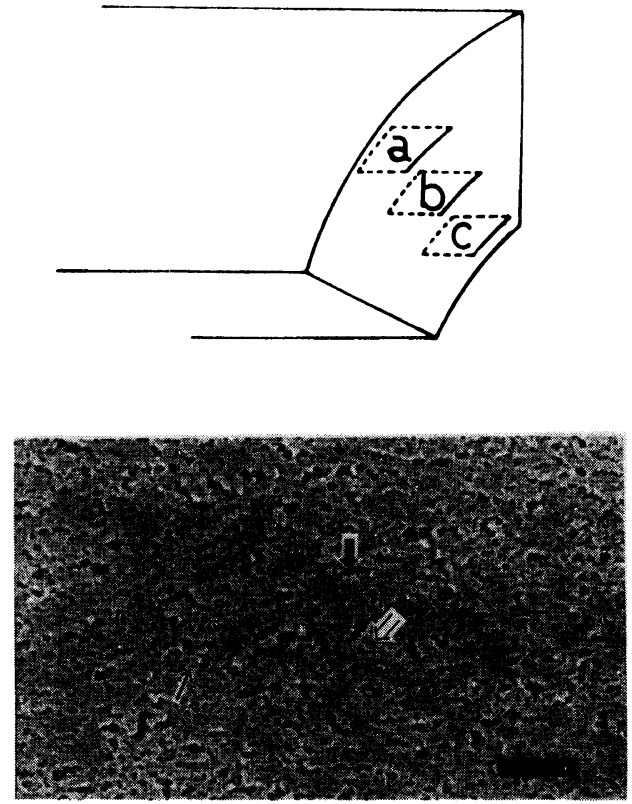

(a)
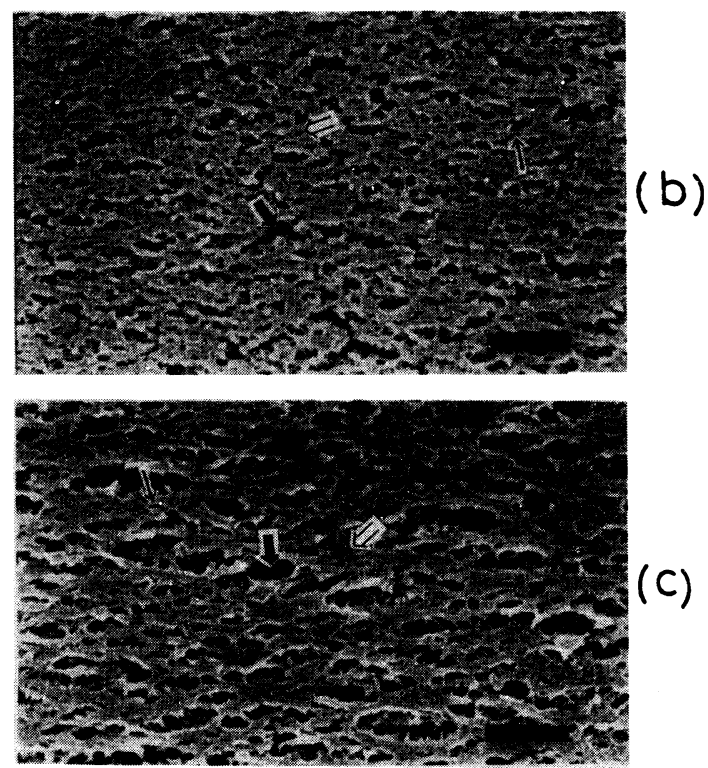

Figure 4. Scanning electron micrographs of positive images for thin sections parallel to $Y Z$ plane (perpendicular to radial axis $X$ ): (a), near the outer surface; (b), near the center of the membrane; (c), near the inner surface. The scale bar is $500 \mathrm{~nm}$ in length. The arrows $\Rightarrow$, $\Rightarrow$ and $\rightarrow$ indicate a large pore with irregular shape, a small circular pore and a fine slit, respectively. 

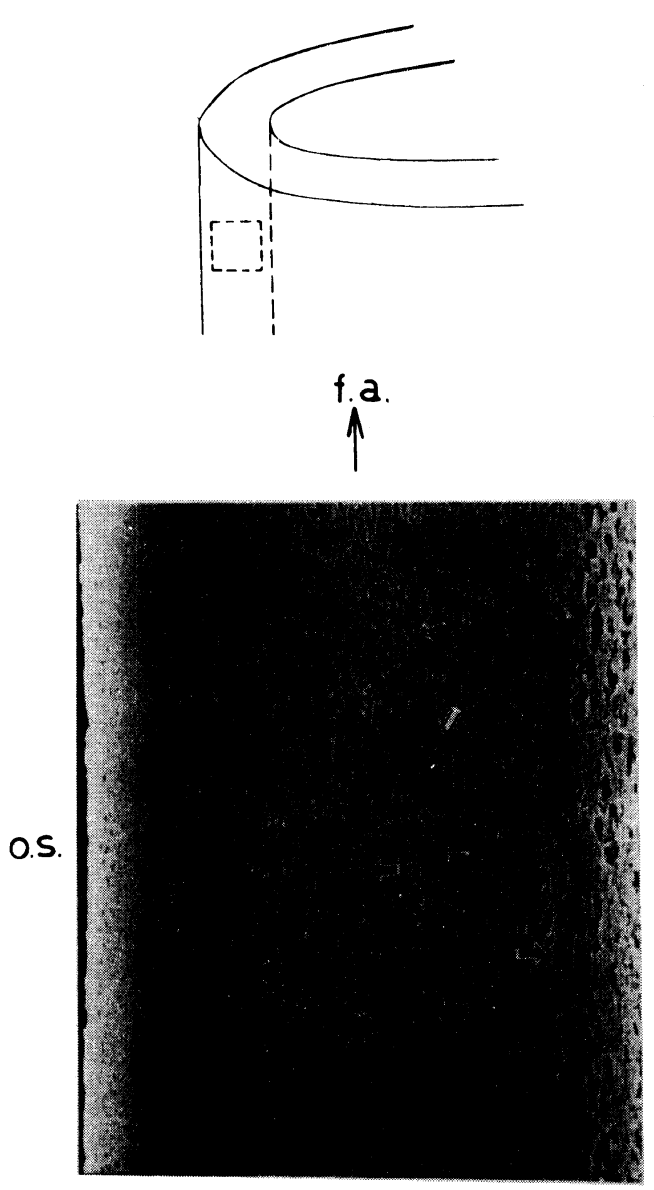

Figure 5. Scanning electron micrograph of positive image for thin section parallel to $X Y$ plane (perpendicular to peripheral axis $Z$ ): The arrows $\Rightarrow$, $\Rightarrow$, and $\rightarrow$ indicate a large pore with irregular shape, a small circular pore and a fine slit, respectively. The symbol f.a. stands for the fiber axis and the scale bar is $5 \mu \mathrm{m}$ in length.

represent a cross sectional view of the cellulose rods observed in Figure 2. These cellulose rods are considered to originate from spheres not by elongation of the fibers during spinning but through other processes such as shrinkage of cellulose during coagulation, refining or drying.

Figures 4, 5, and 6 are positive images of $Y Z, X Y$, and $Z X$ profiles, respectively. The micrographs marked with (a), (b), and (c) in Figure 4 correspond to those near the outer,
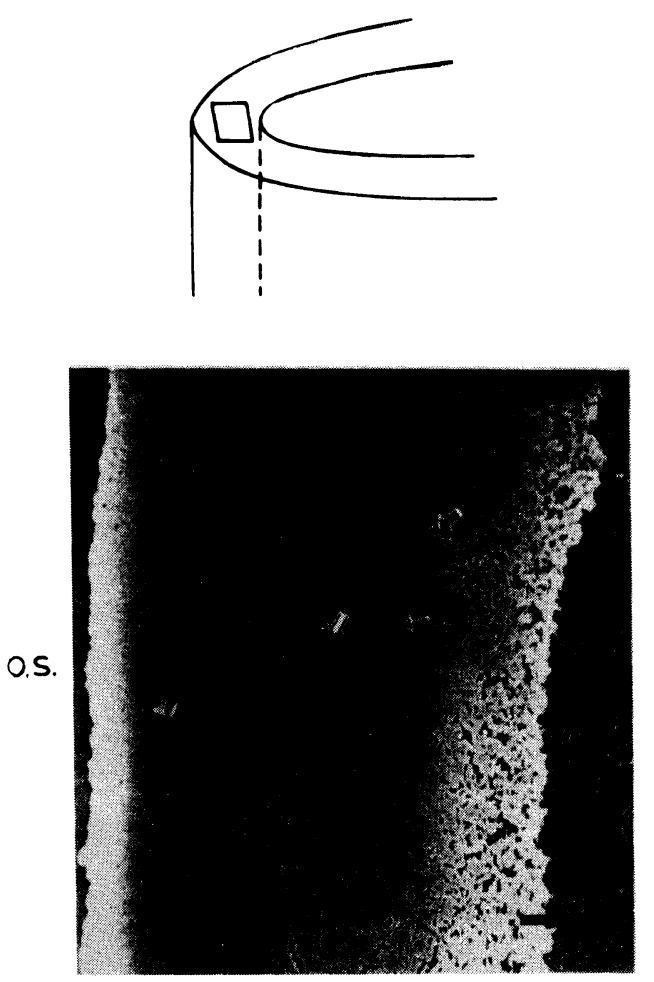

i.s.

Figure 6. Scanning electron micrograph of positive image for thin section parallel to $Z X$ plane (perpendicular to fiber axis $Y$ ): The arrows $\Rightarrow, \Rightarrow$, and $\rightarrow$ indicate a large pore with irregular shape, a small circular pore and a fine slit, respectively. The symbols of i.s. and o.s. stand for the inner and outer surfaces, respectively, and the scale bar is $5 \mu \mathrm{m}$ in length.

the center and the inner surfaces of the membrane, respectively. Comparing the micrographs (a), (b), and (c) in Figure 4, the population density of cellulose substrate is considered to be higher in the area near the outer surface than near the inner surface. In all micrographs in Figure 4, there can be seen large pores with irregular shape (which are considered to be "voids") and small circular pores and fine slits scattered in the cellulosic substrate (which are considered to be "capillaries"). The size of the voids in the micrograph (a) in Figure 4 is smaller than $100 \mathrm{~nm}$, much smaller than that of the voids observed in the micrograph of $Y Z$ profile of BMM. ${ }^{5}$ 
The other remarkable difference between the $Y Z$ profile of i-BMM and that of BMM is the absence of fracture of cellulose substrate in $\mathrm{i}-\mathrm{BMM}$, observed in the micrographs of BMM and considered to be made by elongation of the fiber during spinning. ${ }^{5}$

In Figure 5, there can be seen large slit-like pores, small circular pores and fine slits scattered in the cellulose substrate. Here the slit-like pores are considered to be cross sectional view of "voids". The small circular pores and fine slits are considered to be views of "capillaries" from the axial direction and perpedicular direction to this axis, respectively. In Figure 6 large pores with irregular shape, small circular pores and fine slits can be observed. Here the large pores with irregular shape are considered to be "voids".

Judging from these micrographs of positive images, it can be said that the form of "voids" is polyhedral and their size increases towards the inner surface and that "capillaries" have the shape of small bars and their size is substantially uniform and orientation, isotropic throughout the membrane.

Figures 7, 8, and 9 are negative images of $Z X, Y Z$, and $X Y$ profiles, respectively. The micrographs marked with (a), (b), and (c) in these figures correspond to those near the outer, center and inner surfaces of the membrane, respectively. In all micrographs of Figure 7, large resin blocks of the size ranging between $100 \mathrm{~nm}$ and $1000 \mathrm{~nm}$ with irregular shape and small resin bars having width ranging between $20 \mathrm{~nm}$ and $100 \mathrm{~nm}$ connecting these blocks can be seen. The blocks and bars are considered to be "voids" and "capillaries," respectively. The "voids" increase in size towards the inner surface. In micrograph (a) in Figure 7 the "voids" seem to be located apart from each other, being connected only by "capillaries". This is the characteristic of "neuronic capillaryvoid structures". 5

In all micrographs in Figure 8 there can be seen large resin blocks with size of $100 \mathrm{~nm}$ to $1500 \mathrm{~nm}$, small resin blocks with size of $100 \mathrm{~nm}$

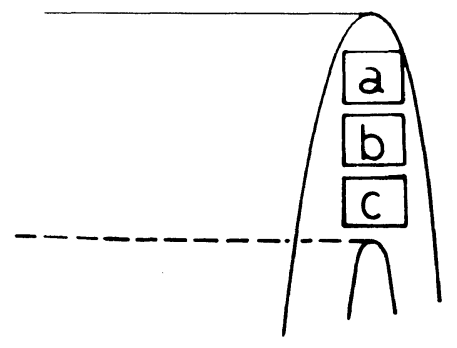

O. S.
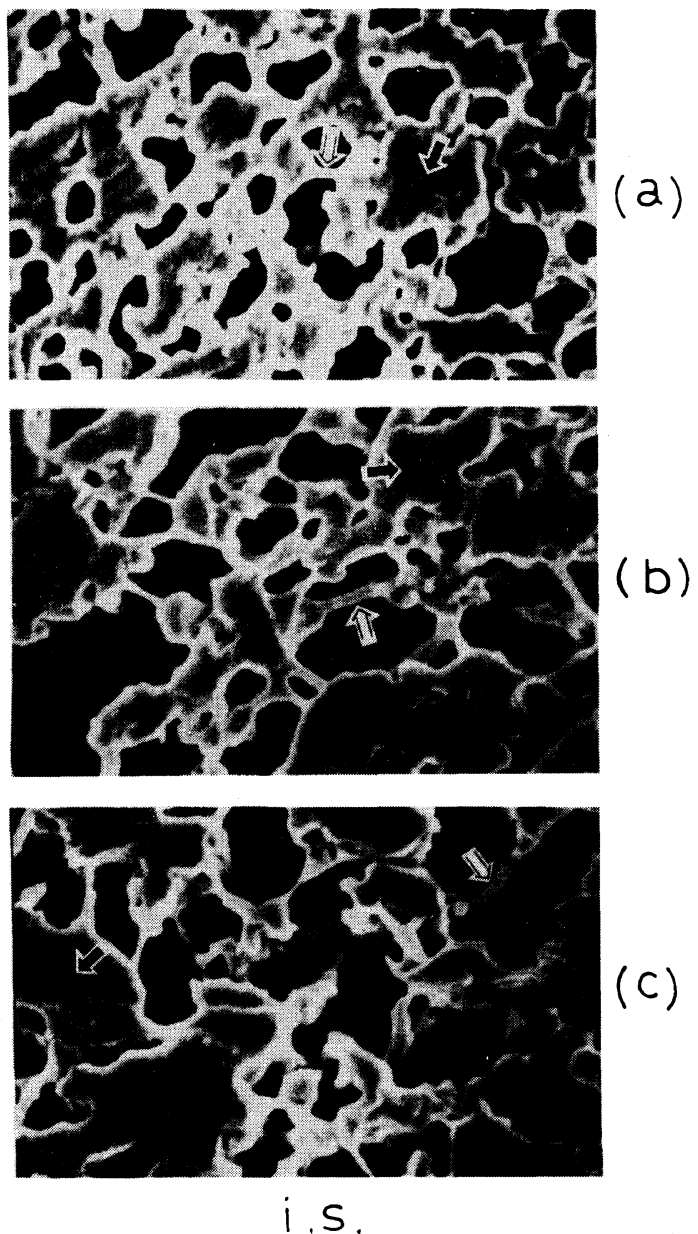

Figure 7. Scanning electron micrographs of negative image for thin sections parallel to $Z X$ plane (perpendicular to fiber axis $Y$ ): (a), near the outer surface; (b), near the center of the membrane; (c), near the inner suface. The arrows $\Rightarrow$ and $\Rightarrow$ indicate a large resin block and small resin bar, respectively. The symbols of i.s. and o.s. stand for inner and outer surfaces, respectively, and the scale bar is $500 \mathrm{~nm}$ in length. 
T. TSURUMI et al.
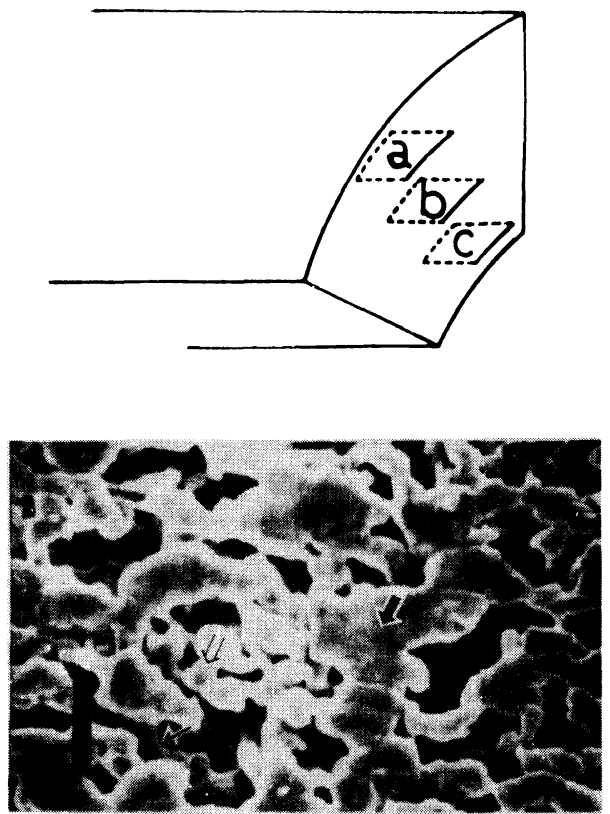

(a)

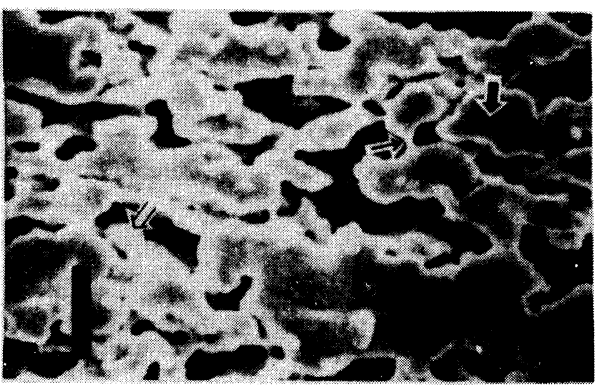

(b)

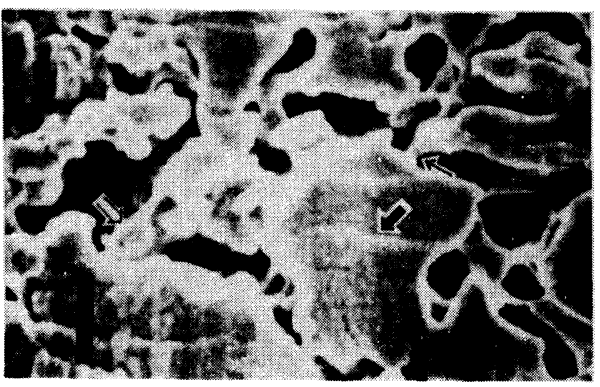

(C)

Figure 8. Scanning electron micrographs of negative image for thin sections parallel to $Y Z$ plane (perpendicular to radial axis $X$ ): (a), near the outer surface; (b), near the center of the membrane; (c), near the inner surface. The arrows $\Rightarrow, \Rightarrow$, and $\rightarrow$ indicate a large resin block, a small resin block and a small resin bar, respectively. The scale bar stands for $500 \mathrm{~nm}$ in length.

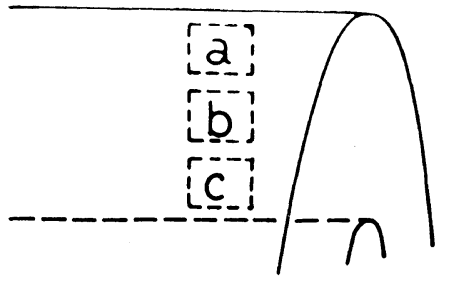

O.S.
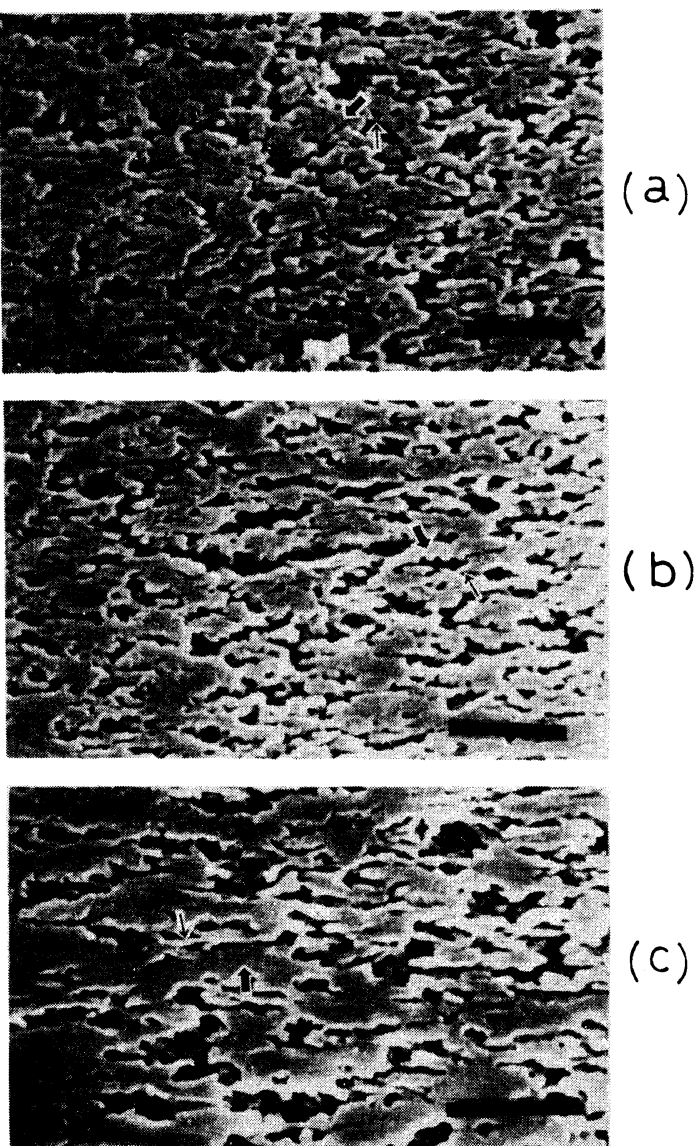

i.s.

Figure 9. Scanning electron micrographs of negative image for thin sections parallel to $X Y$ plane (perpendicular to peripheral axis $Z$ ): (a), near the outer surface; (b), near the center of the membrane; (c), near the inner surface. The arrows $\Rightarrow$ and $\rightarrow$ indicate a resin block and a small resin bar, respectively. The symbols of i.s. and o.s. stand for inner and outer surfaces, respectively, and the scale bar is $500 \mathrm{~nm}$ in length. 
to $300 \mathrm{~nm}$ and small bars with width of $c a$. $50 \mathrm{~nm}$. The large blocks are considered to correspond to the large blocks in Figure 7, and small blocks and small bars are considered to correspond to the small bars in Figure 7.

The micrograph (a) in Figure 9 shows small resin blocks with size of $c a .100 \mathrm{~nm}$ connected by small resin bars with width of $c a .50 \mathrm{~nm}$ and the micrographs (b) and (c) in Figure 9 show slender resin blocks oriented in a direction parallel to the fiber axis and these blocks are connected with each other by small bars. The blocks and bars correspond to "voids" and "capillaries", respectively.

Judging from these micrographs of negative images, it can be said that "voids" have isotropically polyhedral shape near the outer surface but inside of and near the inner surface, they have plate-like shape with plate surface facing the surfaces of the membrane.

Figure 10 shows particle size distribution of cellulose particles measured from Figure 2 . When the position observed approaches the inner surface, the main peak of the distribution shifts gradually to a larger value and two shoulders on the outskirts of the distribution (at $c a .30 \mathrm{~nm}$ and $c a .90 \mathrm{~nm}$, respectively) become apparent. The shoulder at $c a .30 \mathrm{~nm}$ and main peak at $c a .60 \mathrm{~nm}$ may correspond to the primary and secondary particles proposed by Kamide and Manabe, ${ }^{10}$ respectively. The shoulder at $c a .90 \mathrm{~nm}$ may correspond to particles of the third order. We call them "tertiary particles" tentatively.

Figure 11 shows the diameter of a "capillary" measured from Figure 7 compared with those of BMM. The size of the "capillary" is almost the same throughout the membrane. The size of the capillary" for $\mathrm{i}-\mathrm{BMM}$ is larger than that for BMM.

Summerizing the characteristic features of i-BMM discussed above, following conclusions are obtained:

(1) The constructing units of $\mathrm{i}-\mathrm{BMM}$ are cellulose spheres with diameter of $c a .60 \mathrm{~nm}$ and cellulose rods with circular cross sections
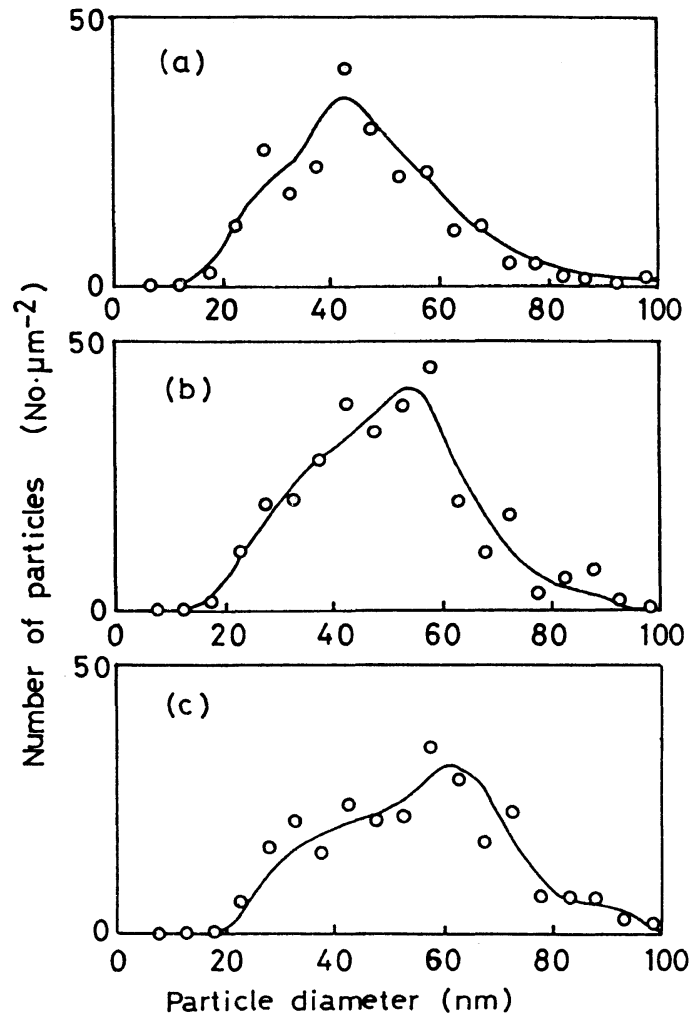

Figure 10. Particle size distribution of cellulose particles for i-BMM and BMM: (a), near the outer surface, (b), near the center of the membrane; (c), near the inner surface.

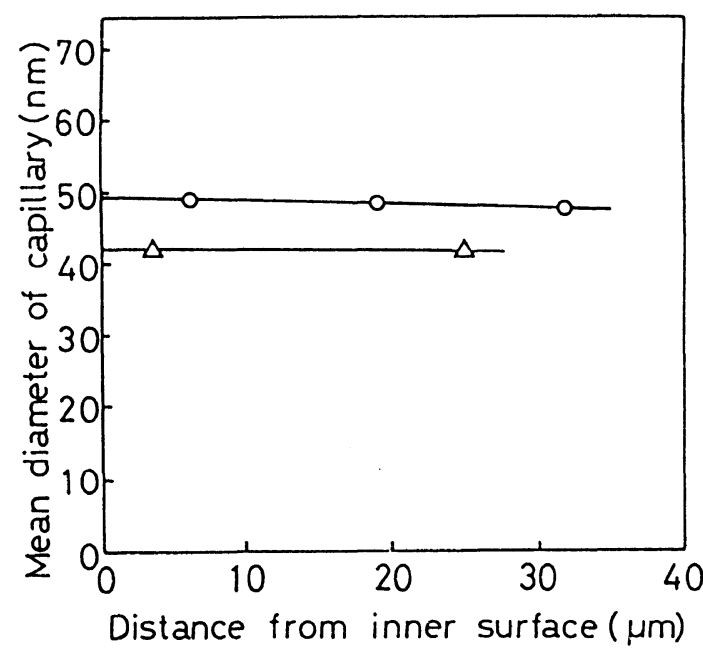

Figure 11. Changes in sizes of "capillary" with distance form the inner surface: $O$, "capillary" of i-BMM; $\triangle$, "capillary" of BMM. 


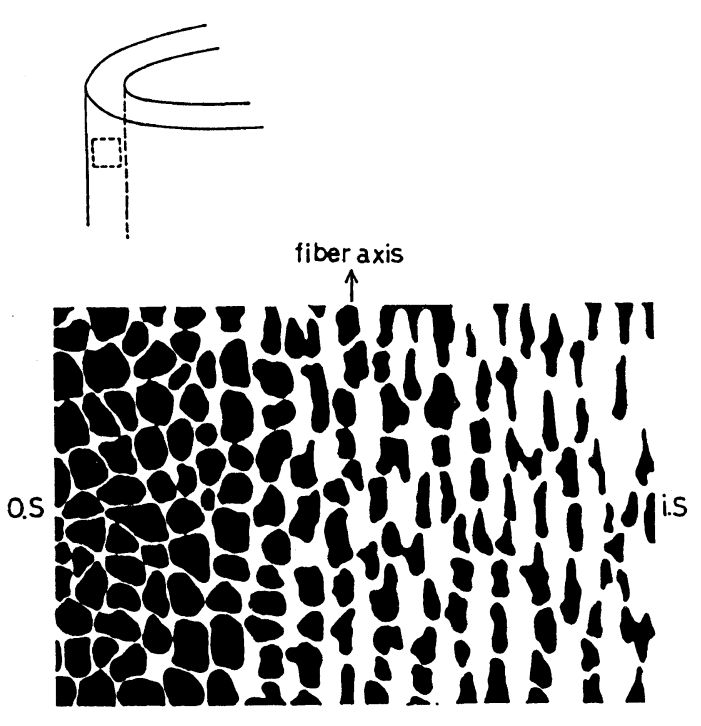

Figure 12. Schematic representation of i-BMM estimated by taking into account the electron mixcrographs. The scale bar stands for $500 \mathrm{~nm}$ in length.

having a diameter of $c a .10 \mathrm{~nm}$. These rods are considered to originate from the spheres.

(2) The "voids" have polyhedral shape and their size increases with increasing distance from the outer surface.

(3) The "capillaries" have the form of small bars and their size is substantially uniform and orientation, isotropic throughout the membrane.

(4) $\mathrm{i}-\mathrm{BMM}$ has a membrane structure of increasing mean pore size with increasing distance from the outer surface (the "gradient structure").

(5) $\mathrm{i}-\mathrm{BMM}$ has a neuronic capillary-void structure" near the outer surface.

Figure 12 shows a schematic representation of the pore structure of i-BMM estimated by taking into accounts electron micrographs and their analysis. The structural characteristics of i-BMM are that it has "gradient structure" and two types of pores of "voids" and "capillaries" with non-elongated shape and that it has a "neuronic capillary-void structure" in the area near the outer surface.

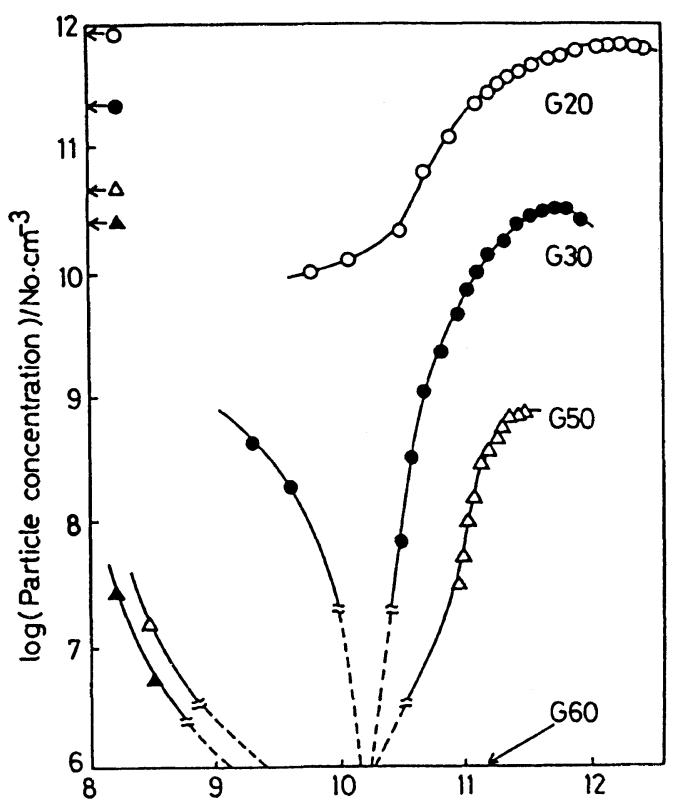

$\log$ (Total number of challenge particles)/No $\mathrm{cm}^{-2}$

Figure 13. Depencence of gold particle concentration of filtrate on total challenge number of this particle $V: O$, $\mathrm{G} 20 ; \bigcirc, \mathrm{G} 30 ; \triangle, \mathrm{G} 50 ; \Delta, \mathrm{G} 60$. The arrows at the ordinate indicate the concentration of gold particles for the original solution before filtration.

\section{Filtration Performance Evaluated Using Gold Particles}

Figure 13 shows the change in gold particle concentration of the filtrate when we increased total challenge number of particles $V$. Figure 14 shows change in the particle logarithmic rejection coefficient $\Phi_{\mathrm{g}}$ with $V$ evaluated from the data in Figure 13. $\Phi_{\mathrm{g}}$ increased in a very small range of $V$ and took maximum value and then decreased gradually. When the $V$ exceeded $10^{11} \mathrm{No} \mathrm{cm}^{-2}, \Phi_{\mathrm{g}}$ showed minimum values of $0.15,0.84$, and 1.88 in cases of three samples of G20, G30, and G50, respectively, and kept a high level of more than 4 for G60.

Table I shows these minimum values compared with those of BMM with mean pore size of $30 \mathrm{~nm}$. Table II shows the number of gold particles caught in the membrane at a given value of $\mathrm{V}$ compared with those of BMM. $^{5}$ i-BMM has the larger capacity of 
catching gold particles than BMM. The point where $\Phi_{\mathrm{g}}$ shows its minimum level is considered the point where the trapping capacity has been fully occupied with gold particles caught and gold particles charged newly start to leak through "channels" formed by the "voids".

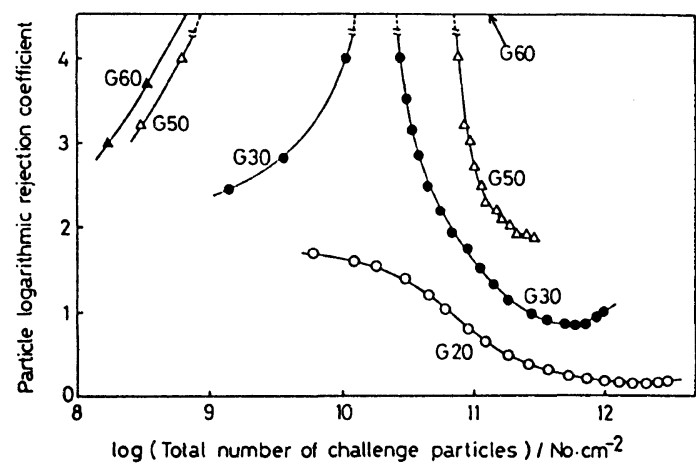

Figure 14. Dependence of gold particle logarithmic rejection coefficient $\Phi_{\mathrm{g}}$ on total challenge number $V$ : $\bigcirc$, $\mathrm{G} 20 ; \bigcirc, \mathrm{G} 30 ; \triangle, \mathrm{G} 50, \Delta, \mathrm{G} 60$.

Table I. Minimum value of $\Phi_{\mathrm{g}}$ for i-BMM and for BMM

\begin{tabular}{ccc}
\hline Gold particles & i-BMM & BMM \\
\hline G20 & 0.15 & 0.05 \\
G30 & 0.85 & 0.28 \\
G50 & 1.85 & 1.78 \\
G60 & 4.00 & 4.00 \\
\hline
\end{tabular}

Then the minimum value of $\Phi_{\mathrm{g}}$ reflects the probability (or population) of "channels" formed by "voids". The higher minimum value means that the population of "channels" is lower. Consequently, i-BMM has the fewer "channels" than BMM.

Figure 15 shows transmission electron micrographs of cross sections of i-BMM after the filtration of G30. With increase in the total challenge number of the particles the density population of the particles increases and the area where a particle can be found expands into the inside of the wall of the membrane. Figure 16 gives the numbers of particles in a unit area of the cross section of $\mathrm{i}-\mathrm{BMM} \mathrm{d} N / d x$ as a function of the distance $x$ from the inner surface. When the challenge number increases, the curve of $\mathrm{d} N / \mathrm{d} x$ vs. $x$ shifts to upper side and to right hand side.

Figures 17 and 18 show transmission electron micrographs of the cross section of i-BMM after filtration and the curves of $\mathrm{d} N / \mathrm{d} x$ vs. $x$ for G60, respectively. The changes of the pattern in Figure 17 and curves of $\mathrm{d} N / \mathrm{d} x v s$. $x$ in Figure 18 are similar to the cases of Figures 15 and 16, respectively. The curve of $\mathrm{d} N / \mathrm{d} x v s$. $x$ reflects the change in pore structure with increase in $x$. According to Yamaguchi et al.'s interpretation for this curve, ${ }^{11}$ the results in Figures 16 and 18 indicate that the pore near

Table II. Total amounts of gold particles caught in i-BMM and BMM per unit filtration area at a given challenge number

\begin{tabular}{|c|c|c|c|c|c|c|}
\hline \multirow{2}{*}{ BMM module } & \multirow{2}{*}{ Gold particles } & \multicolumn{5}{|c|}{ Challenge No. Per unit area/No $\mathrm{cm}^{-2}$} \\
\hline & & $10^{11}$ & $2 \times 10^{11}$ & $10^{12}$ & $2 \times 10^{12}$ & $2 \times 10^{13}$ \\
\hline \multirow[t]{4}{*}{ i-BMM } & G20 & $0.908^{\mathrm{a}}$ & $1.65^{\mathrm{b}}$ & $0.518^{\mathrm{c}}$ & $\mathrm{NT}^{\mathrm{d}}$ & $\mathrm{NT}^{\mathrm{d}}$ \\
\hline & G30 & $0.992^{\mathrm{a}}$ & $1.94^{\mathrm{b}}$ & $0.871^{\mathrm{c}}$ & $\mathrm{NT}^{\mathrm{d}}$ & $\mathrm{Ni}^{\cdot}$ \\
\hline & G50 & $1.0^{\mathrm{a}}$ & $1.99^{\mathrm{b}}$ & $\mathrm{NT}^{\mathrm{d}}$ & $\mathrm{NT}^{\mathbf{d}}$ & $\mathrm{NT}^{\mathrm{d}}$ \\
\hline & G60 & $1.0^{\mathrm{a}}$ & $2.0^{\mathrm{b}}$ & $\mathrm{NT}^{\mathrm{d}}$ & $\mathrm{NT}^{\mathrm{d}}$ & $\mathrm{NT}^{\mathbf{d}}$ \\
\hline \multirow[t]{4}{*}{ BMM } & G20 & $0.834^{\mathrm{a}}$ & $1.47^{\mathrm{b}}$ & $0.436^{\mathrm{c}}$ & $0.798^{e}$ & $0.516^{\mathrm{f}}$ \\
\hline & G30 & $0.942^{\mathrm{a}}$ & $1.69^{b}$ & $0.582^{\mathrm{c}}$ & $\mathrm{NT}^{\mathbf{d}}$ & $\mathrm{NT}^{\mathbf{d}}$ \\
\hline & G50 & $0.996^{\mathrm{a}}$ & $1.98^{b}$ & $\mathrm{NT}^{\mathrm{d}}$ & $\mathrm{NT}^{\mathrm{d}}$ & $\mathrm{NT}^{\mathrm{d}}$ \\
\hline & G60 & $1.0^{\mathrm{a}}$ & $\mathrm{NT}^{\mathrm{d}}$ & $\mathrm{NT}^{\mathrm{d}}$ & $\mathrm{NT}^{\mathbf{d}}$ & $\mathrm{NT}^{\mathrm{d}}$ \\
\hline
\end{tabular}

a $10^{11} \mathrm{Nocm}^{-2}$. b $10^{11} \mathrm{No} \mathrm{cm}^{-2}$. ${ }^{\mathrm{c}} 10^{12} \mathrm{No} \mathrm{cm}^{-2}$. ${ }^{\mathrm{d}}$ Not tested. ${ }^{\mathrm{e}} 10^{12} \mathrm{No} \mathrm{cm}^{-2}$. ${ }^{\mathrm{f}} 10^{13} \mathrm{No} \mathrm{cm}^{-2}$. 


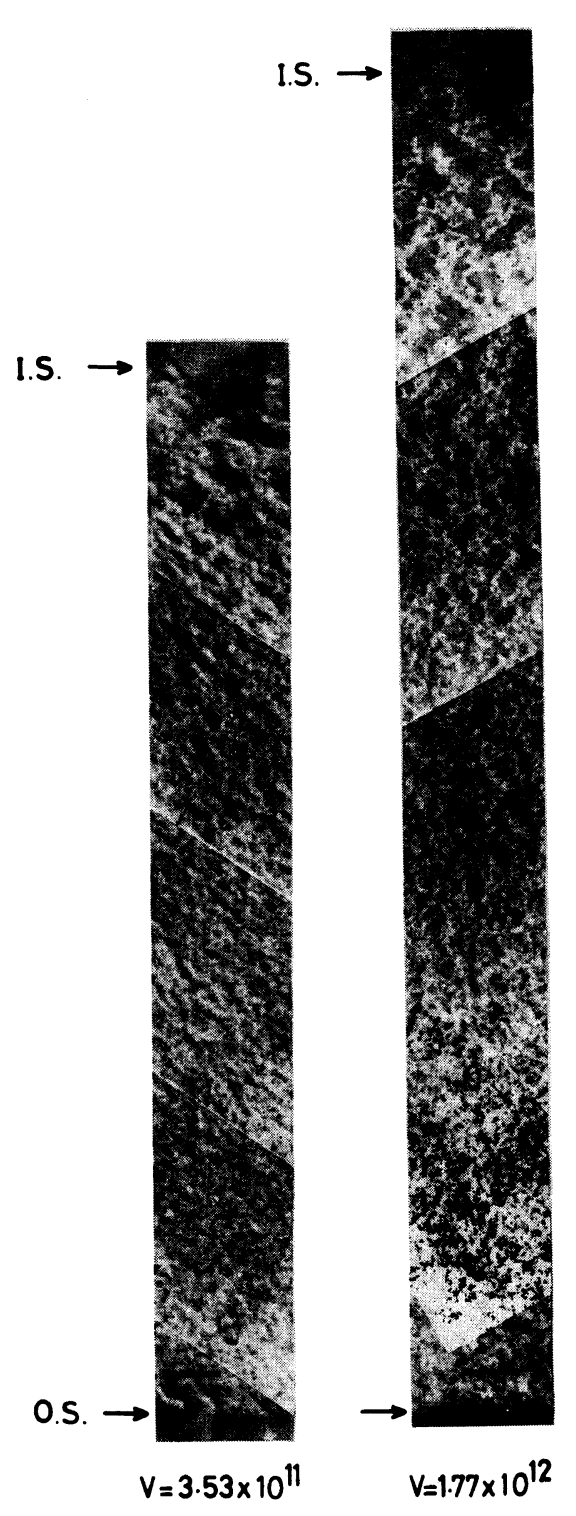

Figure 15. Transmission electron micrographs of cross sections of $\mathrm{i}-\mathrm{BMM}$ after filtration of G30: Left hand side, the thinnest wall part of $\mathrm{i}-\mathrm{BMM}$ after the filtration of $V=3.53 \times 10^{11} \mathrm{No} \mathrm{cm}^{-2}$; right hand side, the thickest part of i-BMM after the filtration of $V=1.77 \times 10^{12} \mathrm{No} \mathrm{cm}^{2}$. The symbols of i.s. and o.s. indicate the inner surface and outer surfaces, respectively. The scale bar stands for $1 \mu \mathrm{m}$ in length.

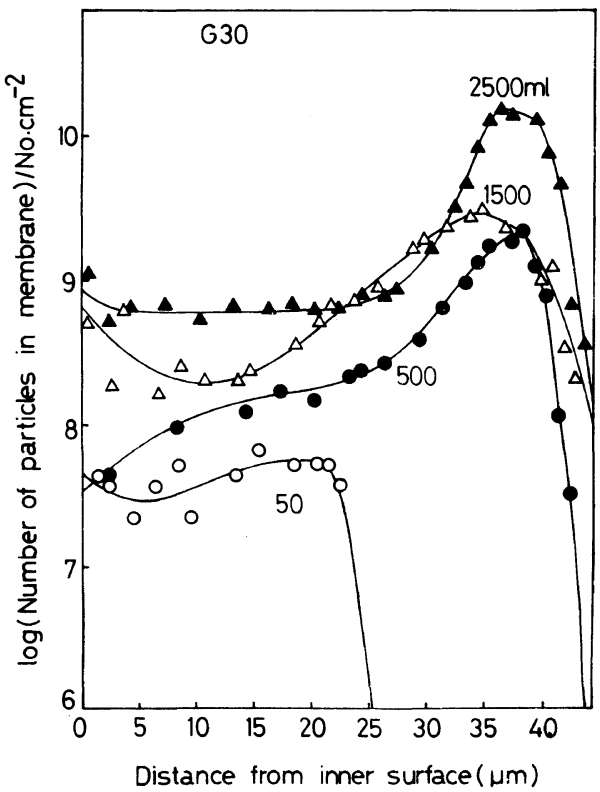

Figure 16. Number of gold particles (G30) in a unit area of cross section of $\mathrm{i}-\mathrm{BMM}(\mathrm{d} N / \mathrm{d} x)$ as a function of the distance from the inner surface $x$ : The figures indicate filtration volume of solution containing G30 with the concentration of $2.12 \times 10^{11} \mathrm{No} \mathrm{ml}^{-1}$.

the inner surface cannot catch particles smaller than $30 \mathrm{~nm}$ but can catch those larger than $60 \mathrm{~nm}$, the pore near the center of the membrane can catch some particles with size of $30 \mathrm{~nm}$ and most larger particles than $30 \mathrm{~nm}$ and the pore near the outer surface can catch most particles larger than $30 \mathrm{~nm}$.

We can generally describe the dependence of $\mathrm{d} N / \mathrm{d} x$ on $x$ as the following approximation equation in declining region of the curve of $\mathrm{d} N / \mathrm{d} x$ vs. $x$,

$$
\mathrm{d} N / \mathrm{d} x=N p_{0} \exp \left(-\mu_{\mathrm{g}} x\right)
$$

where $\mu_{\mathrm{g}}$ is the capture coefficient and independent of $x$ but depends on particles size, total challenge numbers and pore characteristics, and $N p_{0}$ is the extrapolated value of $\mathrm{d} N / \mathrm{d} x$ at $x=0$ and changes depending on filtration conditions and pore characteristics. Table III shows the value of $\mu_{\mathrm{g}}$ when we increased the filtration volume for $\mathrm{G} 30$ and $\mathrm{G} 60$ compared 


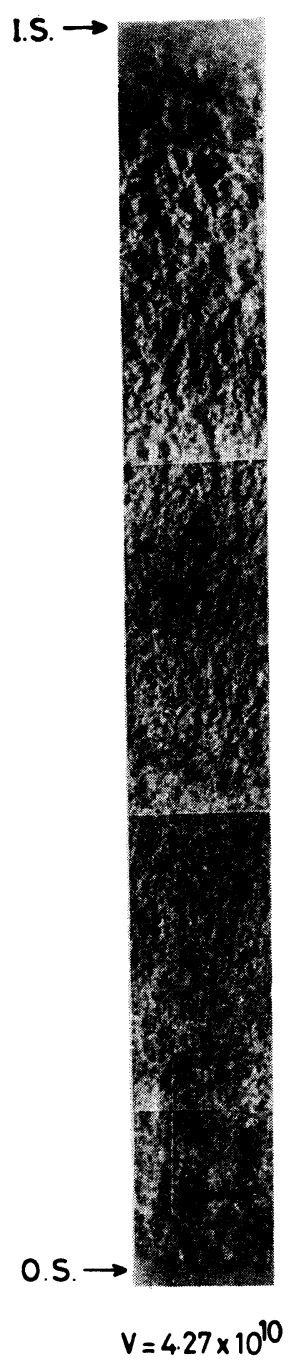

I.S.

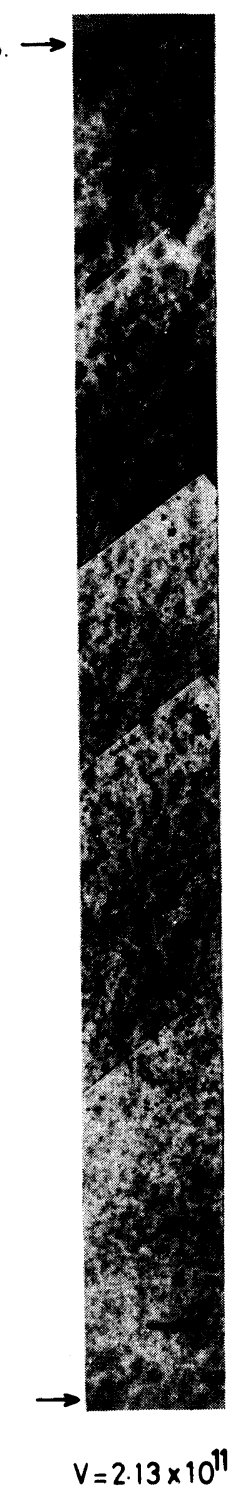

Figure 17. Transmission electron micrographs of cross sections of i-BMM after filtration of G60: Left hand side, the thinnest wall part of $\mathrm{i}-\mathrm{BMM}$ after the filtration of $V=4.27 \times 10^{10} \mathrm{No} \mathrm{cm}^{-2}$; right hand side, the thickest part of i-BMM after the filtration of $V=2.13 \times 10^{11} \mathrm{No} \mathrm{cm}^{-2}$. The symbols of i.s. and o.s. indicate inner surface and the outer surfaces, respectively. The scale bar stands for $1 \mu \mathrm{m}$ in length.

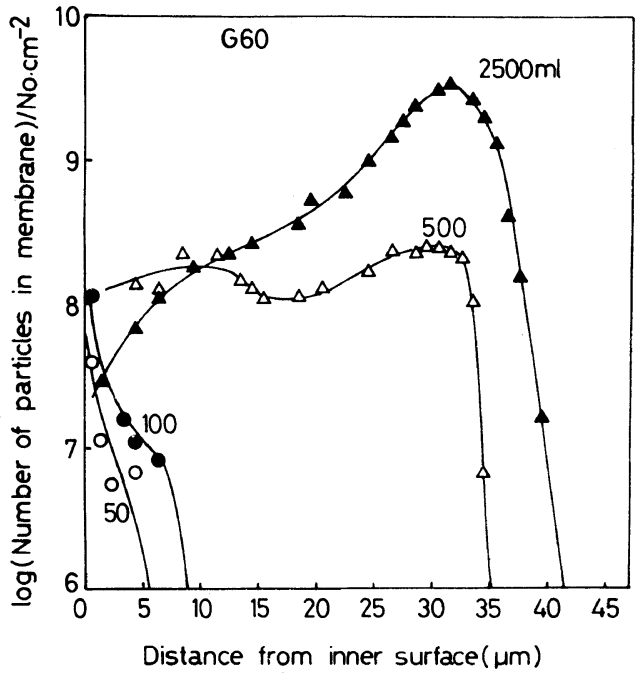

Figure 18. Number of gold particles (G60) in a unit area of cross section of $\mathrm{i}-\mathrm{BMM}(\mathrm{d} N / \mathrm{d} X)$ as a function of the distance from the inner surface $x$ : The figures indicate the filtration volume of the solution containing G60 with a concentration of $2.60 \times 10^{10} \mathrm{No} \mathrm{ml}^{-1}$.

Table III. Capture coefficient $\mu_{\mathrm{g}}$ of G30 and G60 at a given filtration volume

\begin{tabular}{cccc}
\hline \multirow{2}{*}{ Sample } & $\begin{array}{c}\text { Filtration } \\
\text { volume } \\
\end{array}$ & \multicolumn{2}{c}{$\mu_{\mathrm{g}} / \mu^{-1}$} \\
\cline { 3 - 4 } i-BMM & & $\mathrm{G} 30^{\mathrm{a}}$ & $\mathrm{G} 60^{\mathrm{b}}$ \\
\hline \multirow{2}{*}{$\mathrm{BMM}$} & 500 & 1.13 & 2.73 \\
& 1500 & 0.68 & $\mathrm{NT}^{\mathrm{c}}$ \\
& 2500 & 0.90 & 1.19 \\
& 50 & 0.71 & 1.06 \\
& 100 & 0.61 & 1.45 \\
& 500 & 0.68 & 1.46 \\
& 1500 & 0.66 & 0.81 \\
\hline
\end{tabular}

a Concentration of G30 in the filtrand was $2.12 \times$ $10^{11} \mathrm{No} \mathrm{ml}^{-1}$.

b Concentration of $\mathrm{G} 60$ in the filtrand was $2.60 \times$ $10^{10} \mathrm{No} \mathrm{ml}^{-1}$.

c Not tested.

with BMM with mean pore size of $30 \mathrm{~nm}$. The $\mu_{\mathrm{g}}$ of $\mathrm{i}-\mathrm{BMM}$ is larger for the whole range of filtration volume employed for both G30 and G60 than that of BMM. This supports the estimation that $\mathrm{i}-\mathrm{BMM}$ has "neuronic capillary-void structure" with few "channels" 
Table IV. Virus logarithmic rejection coefficient $\Phi_{\mathrm{v}}$ for Japanese encephalitic virus by filtration using BMM at constant transmembrane pressure.

\begin{tabular}{ccc}
\hline \multirow{2}{*}{$\begin{array}{c}\text { Transmembrane } \\
\text { pressure } \\
/ \text { mmHg }\end{array}$} & i-BMM & BMM \\
\cline { 2 - 3 } & & $\Phi_{\mathbf{v}}$ \\
\hline 50 & 5.0 & 1.7 \\
100 & 5.5 & 2.0 \\
200 & 6.1 & 2.5 \\
400 & 5.9 & 3.2 \\
\hline
\end{tabular}

formed by "voids" in the region where the curve of $\mathrm{d} N / \mathrm{d} x$ vs. $x$ shows sharp decline.

\section{Removability Japanese Encephalitis Virus}

Table IV shows the logarithmic rejection coefficient $\Phi_{\mathrm{v}}$ of Japanese encephalitis virus for i-BMM compared with BMM. The average of $\Phi_{\mathrm{v}}$ for i-BMM was 5.6 while that of BMM was 2.4. The filtration pressure gave slight increase in $\Phi_{\mathrm{v}}$.

\section{Permeability of Human Fresh Plasma}

Figure 19(a) shows the filtration time of human fresh plasma necessary for obtaining a given volume of filtrate $F$ for $\mathrm{BMM}$ and $\mathrm{i}-\mathrm{BMM}$. The filtration rate for $\mathrm{i}-\mathrm{BMM}$ is always higher than that of BMM at the same filtration volume $F$. The difference between them increases with increase of $F$. Figure 19(b) shows the plot of the reciprocal filtration rate (i.e., $1 / v\left(\mathrm{~min}^{-2} \mathrm{ml}^{-1}\right)$ ) vs. $F$. The following empirical equation can be reduced approximately for $\mathrm{i}-\mathrm{BMM}$ in the whole range investigated and for $\mathrm{BMM}$ in the initial stage of filtration,

$$
1 / v=1 / v_{0}+\alpha F
$$

where $\left(1 / v_{0}\right)$ is the value obtained by extraporating $1 / v$ into $F=0$ (i.e., $t=0$ ) and $\alpha$ is a constant independent of $v$ but dependent on pore structure. The values of $v_{0}$ and $\alpha$ were $118 \mathrm{ml} / \mathrm{m}^{2} \mathrm{~min}$ and $6.9 \times 10^{-4} \mathrm{~m}^{2} \mathrm{~min} \mathrm{ml}^{-2}$ for $\mathrm{i}-\mathrm{BMM}$ and were $105 \mathrm{ml} \mathrm{m}^{-2} \mathrm{~min}$ and $1.1 \times$ $10^{-3} \mathrm{~min} \mathrm{ml}^{-2}$ for $\mathrm{BMM}$, respectively. The
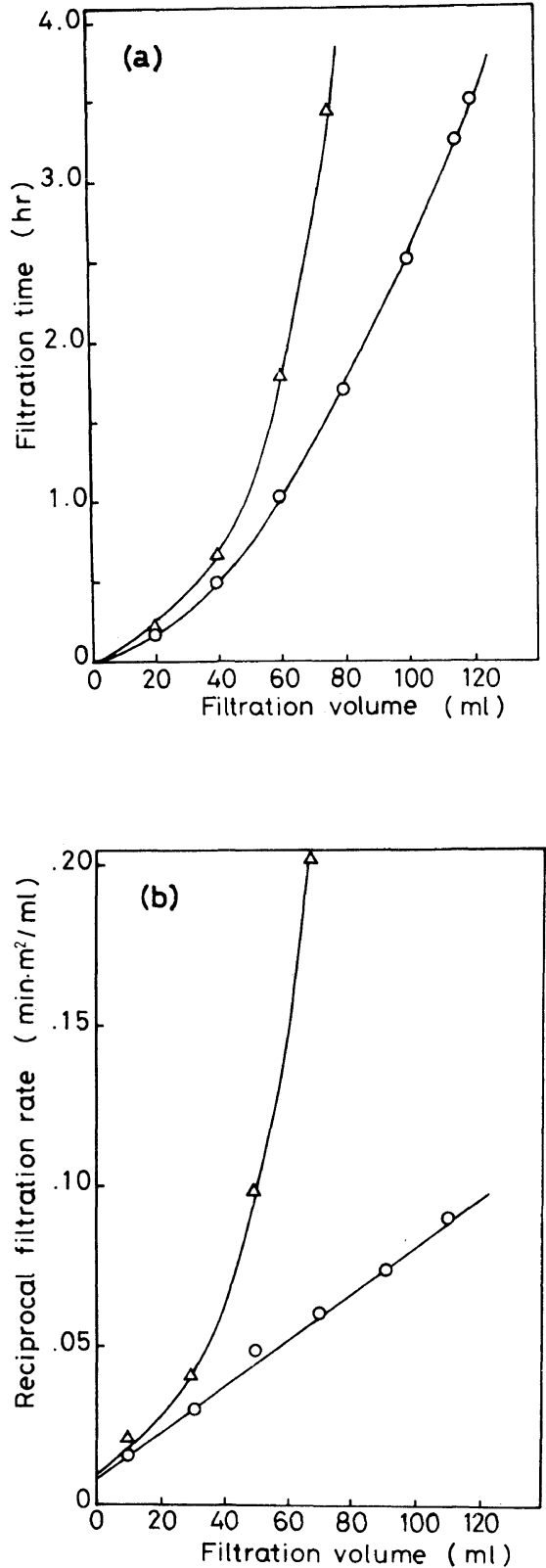

Figure 19. Filtration characteristics of human fresh plasma for i-BMM and BMM: $\bigcirc, \mathrm{i}-\mathrm{BMM} ; \triangle$, BMM; (a), dependence of filtration time for getting a given volume of filtrate under the constant transmembrane pressure of $0.15 \mathrm{~atm}$ on filtration volume; (b), dependence of reciprocal filtration rate on filtration volume. 
Pore Structure and Filtration Performances of Improved BMM

Table V. Sieving coefficients of plasma proteins for i-BMM and BMM

\begin{tabular}{|c|c|c|c|c|c|c|c|c|c|c|c|c|c|}
\hline \multirow{2}{*}{ Sample } & Time $^{\mathbf{a}}$ & $\mathrm{ALB}^{\mathrm{b}}$ & $\mathrm{IgG}^{\mathrm{c}}$ & $\operatorname{IgA}^{\mathrm{d}}$ & $\operatorname{IgM}^{e}$ & $\mathrm{Fbn}^{\mathrm{f}}$ & FIX $^{\mathrm{g}}$ & ATIII $^{\mathbf{h}}$ & $\mathrm{FbN}^{\mathrm{i}}$ & $\mathrm{HDL}^{\mathrm{j}}$ & $\mathrm{LDL}^{\mathbf{h}}$ & VLDL $^{1}$ & T.P. ${ }^{m}$ \\
\hline & $\min$ & $\%$ & $\%$ & $\%$ & $\%$ & $\%$ & $\%$ & $\%$ & $\%$ & $\%$ & $\%$ & $\%$ & $\%$ \\
\hline \multirow[t]{6}{*}{ i-BMM } & 20 & 97 & 86 & 96 & 91 & 84 & 83 & 101 & 97 & 106 & 77 & 32 & 98 \\
\hline & 40 & 92 & 91 & 86 & 89 & 112 & 76 & 87 & 80 & 94 & 73 & 32 & 92 \\
\hline & 60 & 92 & 78 & 84 & 76 & 87 & 67 & 76 & 74 & 96 & 66 & 34 & 92 \\
\hline & 80 & 97 & 80 & 85 & 79 & 82 & 72 & 92 & 78 & 91 & 67 & 33 & 95 \\
\hline & 100 & 97 & 93 & 87 & 81 & 73 & 73 & 94 & 72 & 94 & 67 & 33 & 95 \\
\hline & 120 & 97 & 94 & 88 & 75 & 79 & 76 & 94 & 74 & 97 & 71 & 24 & 95 \\
\hline \multirow[t]{4}{*}{ BMM } & 20 & 89 & 83 & 79 & 75 & 76. & 70 & 86 & 54 & 83 & 56 & 23 & 86 \\
\hline & 40 & 89 & 73 & 65 & 47 & 54 & 68 & 81 & 42 & 73 & 28 & 15 & 83 \\
\hline & 60 & 97 & 74 & 72 & 41 & 39 & 71 & 87 & 41 & 80 & 26 & 8 & 88 \\
\hline & 75 & 103 & 74 & 77 & 41 & 35 & 74 & 91 & 39 & 89 & 26 & 8 & 93 \\
\hline
\end{tabular}

a Filtration time. b Albumin. ' Immunoglobulin G. ' Immunoglobulin A. ' Immunoglobulin M. ${ }^{\text {f Fi- }}$ brinogen. ${ }^{\text {g }}$ Factor IX. ${ }^{\text {h }}$ Antithrombin III. ${ }^{\mathbf{i}}$ Fibronectin. ' High density lipoprotein cholesterol. ${ }^{\mathbf{k}}$ Low density lipoprotein cholesterol. ${ }^{1}$ Very low density lipoprotein cholesterol. ${ }^{m}$ Total protein.

value of $v_{0}$ corresponds to the initial filtration rate and $\alpha$ reflects increase of filtration resistance due to increase in mass retained in the membrane. Then, the initial filtration rate of BMM and $\mathrm{i}-\mathrm{BMM}$ is considered to be nearly the same. The smaller value of $\alpha$ for i-BMM indicates that even when the same amounts of particles are fed to both membranes, the effect of particles to decrease filtration rate is smaller for i-BMM.

Table $\mathrm{V}$ indicates that the permeability of proteins for $\mathrm{i}-\mathrm{BMM}$ is larger than that of BMM for all proteins evaluated.

\section{Relationship between Pore Structure and Per- formances}

The i-BMM prepared under spinning conditions not so as to impose stretching force on the fiber proved to have higher performances in protein permeability and virus removability than BMM. Structural differences between $\mathrm{I}-\mathrm{BMM}$ and BMM which might have caused these differences in their performances are as follows:

(1) Wall thickness, that of $\mathrm{i}-\mathrm{BMM}$ is $35 \mu \mathrm{m}$ and that of BMM $25 \mu \mathrm{m}$.

(2) i-BMM has a "neuronic capillary-void structure."
(3) i-BMM has a "gradient structure".

Generally virus removability is in a contradictory relationship with protein permeability. That is, if the wall thickness of the membrane is made two times larger when the membrane structure is kept constant, virus removability represented by virus logarithmic rejection coefficient $\Phi_{\mathrm{v}}$ will become two times larger but protein permeability (both filtration rate and recovery rate) will decrease. $\mathrm{i}-\mathrm{BMM}$ has 1.4 times as large wall thickness as BMM. But $\Phi_{v}$ of $\mathrm{i}-\mathrm{BMM}$ is almost 2.3 times that of $\mathrm{BMM}$ and its protein permeability is higher than that of BMM. Then the wall thickness cannot be the reason for the better performances of $\mathrm{i}-\mathrm{BMM}$ compared with BMM.

The diameter of the "capillary" is the main factor to decide the size of the particle such as gold or virus which can pass through the membrane with the "neuronic capillary-void structure", because such a membrane dose not have "channels" formed by "voids" of much larger pore size than "capillaries". In this type of membrane the particles with diameter equal to or larger than that of "capillaries" plug "capillaries" easily and even thin membrans would exert high removability against particles. Then the "neuronic capillary-void structure" 
may be the main reason for the higher virus removability of i-BMM.

However, the membrane only with the "neuronic capillary-void structure" may have lower protein permeability than the membrane with "channels" formed by "voids" because "capillaries" will be plugged with proteins and accumulation of proteins on the membrane surface will occur more easily and quickly for the former than the latter. But i-BMM has a "gradient structure" in addition to a "neuronic capillary-void structure". Then proteins with larger particle size than the size of "capillaries" will be plugged or trapped in pores located on the upperside in the fiow stream in the membrane. That is, as the pore size of the membrane decreases gradually from the inner surface to the outer surface, protein particles will be caught on the way between the inner surface and outer surface in the order of particle size. This is considered the reason the filtration rate for $\mathrm{i}-\mathrm{BMM}$ is kept higher than BMM. In addition to this, the larger "capillary" size of i-BMM may make some contribution to higher protein permeability.

It can be concluded that the proper combination of "neuronic capillary-void structure" and "geadient structure" is the main reason for higher performances of i-BMM compared with BMM. However, there may be many other variations on combining these two structures and by selecting the best combination, we will be able to obtain a membrane with much better performance.

\section{REFERENCES}

1. K. Kamide and S. Manabe, Polym. J., 13, 459 (1981).

2. Y. Hamanoto, S. Harada, S. Kobayashi, K. Yamaguchi, H. Iijima, S. Manabe, T. Tsurumi, H. Aizawa, and N. Yamamoto, Vox Sang., 56, 230 (1989).

3. S. Manabe, T. Tsurumi, G. Ishikawa, M. Satani, T. Yamashiki, Y. Hamamoto, K. Yamaguchi, S. Kobayashi, and N. Yamamoto, Membrane, 14, 77 (1989).

4. S. Sekiguchi, K. Ito, M. Kobayashi, H. Ikeda, T. Tsurumi, G. Ishikawa, S. Manabe, M. Satani, and T. Yamashiki Membrane, 14, 253 (1989).

5. T. Tsurumi, N. Osawa, H. Hitaka, T. Hirasaki, K. Yamaguchi, S. Manabe, and T. Yamashiki, Polym. J., 22, 751 (1990).

6. T. Tsurumi, N. Osawa, T. Hirasaki, K. Yamaguchi, S. Manabe, and T. Yamashiki, Polym. J., 22, 304 (1990).

7. S. Manabe, M. Iwata, and M. Inoue, Japanese Patent Application, 58-89625 (1983).

8. T. Tsurumi and S. Ide, Japanese Patent Application, to be applied.

9. G. Frens, Nature Phys. Sci., 241, 20 (1973).

10. K. Kamide and S. Manabe, "Materials Science of Synthesis Membrane," D. R. Lloyed, Ed., American Chemical Society, Washington D. C., 1985, p 197.

11. K. Yamaguchi, T. Hirasaki, T. Tsurumi, S. Manabe, G. Ishikawa, T. Sato, and M. Satani, Membrane, to be submitted. 